\title{
E-Commerce Purchase Intention in Emerging Markets: The Influence of Gender and Culture
}

\author{
Dimitrios Rigas and Nazish Riaz \\ University of West London, W5 5RF, UK \\ \{Dimitrios.Rigas, Nazish.Riaz\}@uwl.ac.uk
}

\begin{abstract}
This paper explores the external factors that influence the decision making process of young Asian females when they shop online for fashion clothing. The empirical investigation was carried out with a positivistic approach and a sample size of 142 young females in Pakistan. As females get more financially independent in developing Asian nations it leads to a question whether their buying decisions are still dominated by external factors? It was found that young educated adult Pakistani females make on-line purchase decisions under a significant influence of a highly collective and masculine environment. These results could be extrapolated to other similar cultures and emerging e-retailing areas.
\end{abstract}

Keywords: Socio-technical issues, e-commerce user interfaces, culture, purchase behavior, consumer behavior, emerging markets, decision-making process, theory of reasoned action.

\section{$1 \quad$ Introduction}

It is widely common in the developed world that women make independent e-retailing decisions. However, for some developing countries (e.g. Pakistan) the female buying behavior appears to be affected by cultural variables (e.g. masculinity). According to Bearden et al. [1], the most important determinant of an individual's behavior is the influence of another individual.

This study has taken an opportunistic Pakistani female user sample. This retail market was approximated at 42 billion USD reporting an annual sales growth of approximately 105 million USD (Punjab Board of Investment and Trade 2013). This indicates an increase in economic growth and spending power of consumers. One of the most important contributing factors towards this new consumption pattern is the young generation, which account for $73 \%$ of the total population (under 35 years of age) of which 33,632,395 are females [2].

Previous studies examined the influence of cultural variables to buying behavior and purchase decision-making of consumers. These include family structure and size, religion, and collectivism. Bearden et al. [1] suggest that the most important determi-

adfa, p. 1, 2011.

(C) Springer-Verlag Berlin Heidelberg 2011 
nant of an individual's consuming behavior is the influence of others. Cultural and idiosyncratic values often influence e-commerce user behavior $[3,4,5]$. This type of influence distils into a shared set of on-line consumer decision-making values [6] that pass on from generation to generation [7,8]. Bagozzi et al. [9] define it as a combination of social and psychological processes that people endure through the acquisition, use and disposal of products, practices or services. These processes also gender dependent [10] with different needs and behavior of consumption [11]. Culture is another influencing parameter [12]. It involves conscious and unconscious values, attitudes, ideas and symbols that help to shape up on-line consumer behavior.

The understanding of these influencing factors to consumer behavior in emerging markets is particularly important for the development of e-commerce interfaces. This paper aims to understand these issues better.

\section{Culture and e-Commerce}

In emerging e-commerce markets, such as the one in Pakistan that this study has focused, male dominance influences women decisions. As there is lack of education and less awareness amongst women in the urban and rural areas, the success of e-commerce is not as in the Western countries. However, the e-commerce platforms and e-commerce interfaces are on the rise and slowly businesses have started to have their presence on the web. This has been a result of the multimodal interfaces and avatars, which as described by Rigas and Alty [19] help to communicate with the target audience. Moreover, Rigas [20] supported the idea of auditory and ear-cons in the user interfaces for effective communication. These additions could play a vital role in an emerging e-commerce market such as the one in Pakistan.

\subsection{Hofstede Cultural Typology}

Hofstede Cultural Typology, as shown in Fig. 1, shows five points through which the culture of a country can be analyzed. The higher the number the more that aspect is persistent in the culture. Power distance indicates the degree to which the less powerful and dominant members of the society accept the power to be distributed unequally. High power distance indicates that all the individuals are not dealt with equality. The level of inequality is usually sanctioned equally by the leaders and the followers. Individualism reflects the extent to which the individuals of a particular society are bonded into groups.

In an individualistic culture, the members of a society are mainly concerned only about their own interests and do not take into consideration the interests of other members of the society. Whereas, a society having a collectivist culture is more interested in the interest of its group into which they are strongly bonded. Personal interest, likes and dislikes are usually overlooked and ignored for the sake of common interest of the group in such a society. 


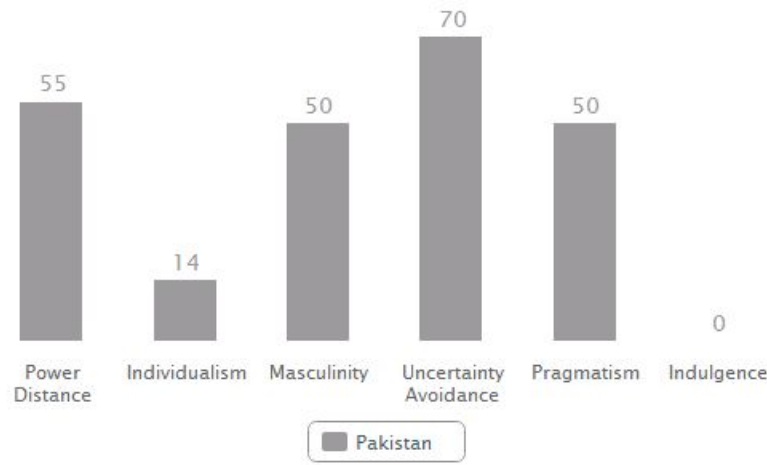

Fig. 1. Hofstede's Cultural Dimension [21]

Pakistan displays a collectivist culture. A study on China found that collectivist values influence the purchasing decision most [22] It is believed that due to being a highly collective society, the basic norms and values shared amongst the society and the suggestions and likes or dislikes of close family members are of great value and influence when a Pakistani individual would make a purchase decision. Pakistan being a masculine society not only interrelates its values with the role of men but is also to a great extent influenced by the dominance of men and their super ordinate position over females. This context makes the male dominance and the power of men a predominant factor, which is likely to affect the purchase decision of Pakistani women.

\subsection{ABC Model of Attitude}

Pakistan, which has a very collectivist culture, people tend to form attitudes that full fill their social identity functions, and there is not a constant relationship between attitude and future behavior $[13,14]$. There can be a possibility of having a converse relationship, where the behavior would come first determining the attitude. In a collectivist culture, the shared experiences within a group of a particular brand or product would be more influential as compared to an individualistic culture [15]. Hence, it is assumed that within a Pakistani society, women have a standard learning hierarchy approach, as illustrated in the diagram above, when making purchase decision and they carry out an extensive problem solving process before making a purchase.

Considering the notion of culture suggested by Hofstede [21] as "collective programming of the mind" it is then important to understand culture by further studying attitudes, beliefs and values which are shared amongst certain group of people. Attitude is a cultured and learned tendency to react or respond in a consistent and steady manner towards a given article or object. 


\section{User Study: Results, Discussion and Analysis}

A positivist approach was taken in this study. A structured questionnaire was designed to investigate the different stages of the decision-making purchasing process and input variables to this process of young adult females. The sample was opportunistic and taken in Pakistan. It consisted of 142 female respondents aged between 18 and 35 years old. This age profile of respondents consisted of 26-30 years old (36.1\%), 21-25 (35.4\%) and 18-20 (4.9\%) as shown in Fig. 2. Fig. 2. shows the educational profile of the sample. It consisted of 65 respondents $(45.5 \%)$ with a postgraduate qualification and $40(28 \%)$ with an undergraduate education. The results are discussed in relation to the purchase decision-making process, attitudes and the theory of reasoned action. Results indicated that from the age of 26 onwards, their spouses will influence their purchasing decision-making process of potential e-commerce female users. Females aged between 21 and 25 are more likely to be influenced by males members of their family (e.g. fathers or brothers).

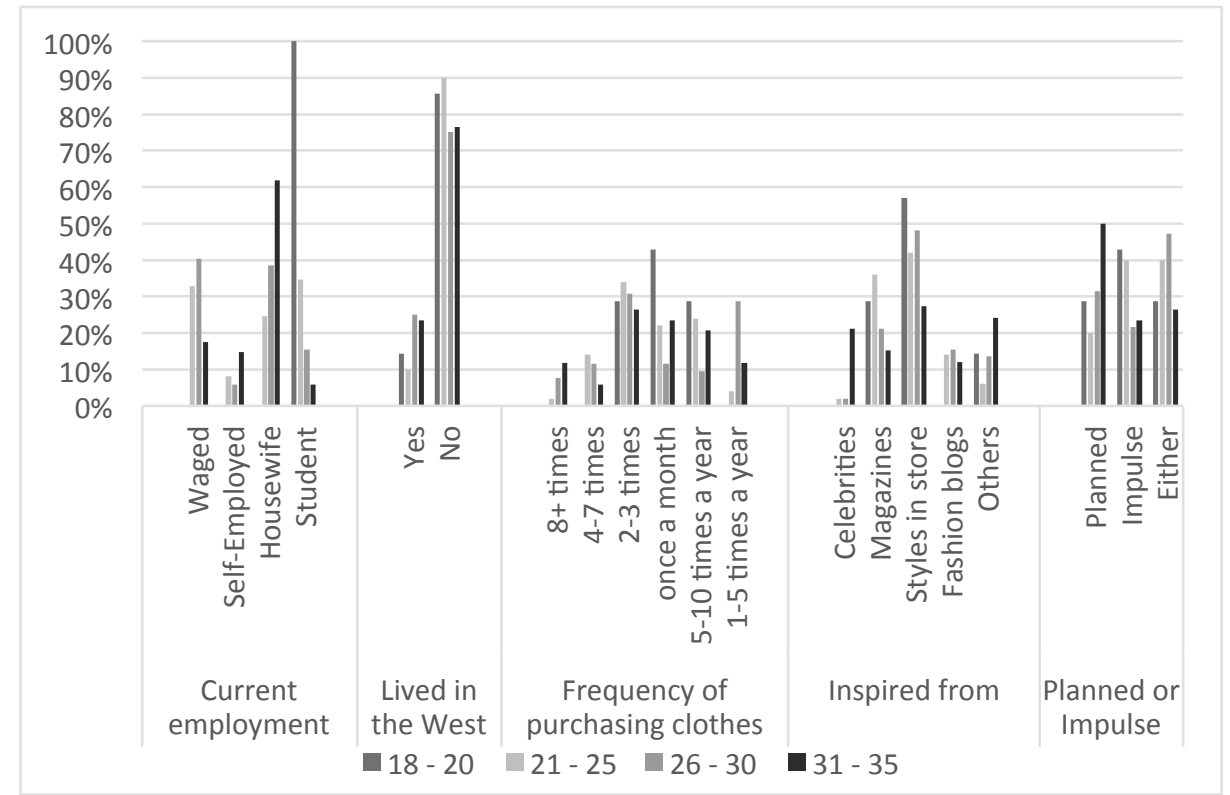

Fig. 2. Sample Profile against Age

A total of 144 respondents took part in the survey consisting of females only between the ages of 18-35. 142 respondents gave valid responses (98.6\%) and two gave invalid responses (1.4\%). The first largest group (36.1\% of respondents) who filled in the questionnaire were aged 26-30. The second largest group (35.4\% of respondents) were aged 21-25. The smallest group (4.9\%) was aged 18-20. The majority of females (aged 21-25) were single and considered themselves independent to make their own decisions regarding purchasing fashion clothing on on-line and offline. However, the 
analysis suggests that these females are actually most dependent and influenced by males. This can be related to the fact that single women usually live with their family and hence there are more men who can influence their decisions such as their father, brothers or uncles or even males from the extended family.

\subsection{Sample profile against Marital Status}

A cross tabulation between age group and marital status, as shown in Fig. 3, indicates that the highest percentage of married females $(21.0 \%)$ were between the ages of $31-35 ; 19.6 \%$ between ages $26-30$; and the highest percentage of single females (21.7\%) between ages 21-25. Results suggest that from the age of 26 onwards, it is more likely that Pakistani females are married and hence may be more likely to be influenced by males, specifically their husbands in their decision making process. However at the age of 21-25 they are either staying at home and influenced by other males of the family such as father or brothers or are relatively independent compared to married females. In a masculine society females tend to spend more time at home and in domestic activities and also tend to face gender inequality. Married females in a collective and masculine society of Pakistan are believed to be dominated by their husbands, where men not only take control over most of the house matters but also purchasing their clothes. In the buying decision process, women not only look for more information but also take more options into consideration, making the process more complex.

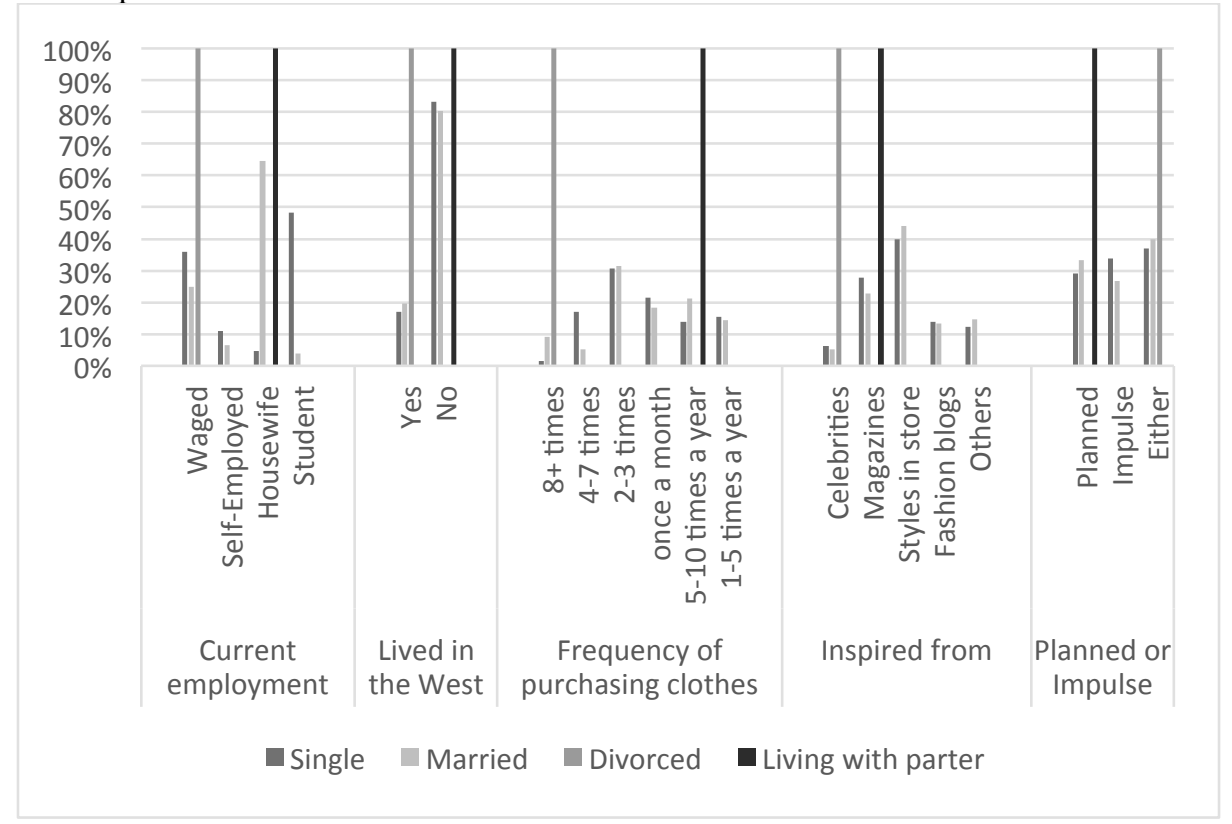

Fig. 3. Sample Profile against Marital Status 
Results also suggest that married females were significantly influenced by their husbands (only) when making decisions for purchasing fashion clothing. The fact that females cannot purchase against the will of their father or husband, who are considered the 'head of the house' in Pakistani society, may influence this. Consequently, Pakistani females try to consume products, which are accepted by their husbands, fathers, or other family members.

\subsection{Decision Making Factors against Age Group}

In a collective society, most young adult women do not live on their own, but there are a number of few females who live outside of their families. Some live because of their jobs and some live away from their families because of their studies. To have a better understanding of the influences which young women have on them whilst making a purchase decision the age group to which they belong and with whom they live with has been crosstublated in Fig. 4. From the same Fig. 4. it can be seen that $61.0 \%$ live with their family. $24.8 \%$ disagree that they make independent decisions in the absence of influence of males. Only 5.7\% of those staying at home agreed that they make independent decisions in the absence of male influence. $14.9 \%$ of respondents living with their spouses disagreed that they make independent decisions and only $2.1 \%$ agreed that their decisions are independent. Whereas it can be seen that only 1 respondent, living alone, claimed that she makes independent decisions and surprisingly $2.1 \%$ females living alone, the samples shows that they were influenced by males when making their purchase decisions. It was expected that young women living with their family or husband are likely to be influenced by men, but these results have strongly revealed the influence that men have even to those females living alone. This indicates the strong influence and that, women tend not to overlook or avoid the influence of men when purchasing.

Results show that $29.7 \%$ of young women living with their families agreed that they consider other people's opinions when they making purchasing decisions. However, $15.9 \%$ disagree that they consider other's opinions. This can be due to many factors. Within a family, other's opinions matter. For example, if an uncle lives in the same house the tradition in a collectivist society is to take their opinion and ideas. For clothing, the aunt would be involved in giving her opinions for purchasing. If that clothing is bought against her approval it may lead to conflict, therefore allot of sensitivity is involved. However in e-commerce, women do not seek much permission and approval, because purchases on the internet are favored by friends or reviews that recommend others to purchase. 


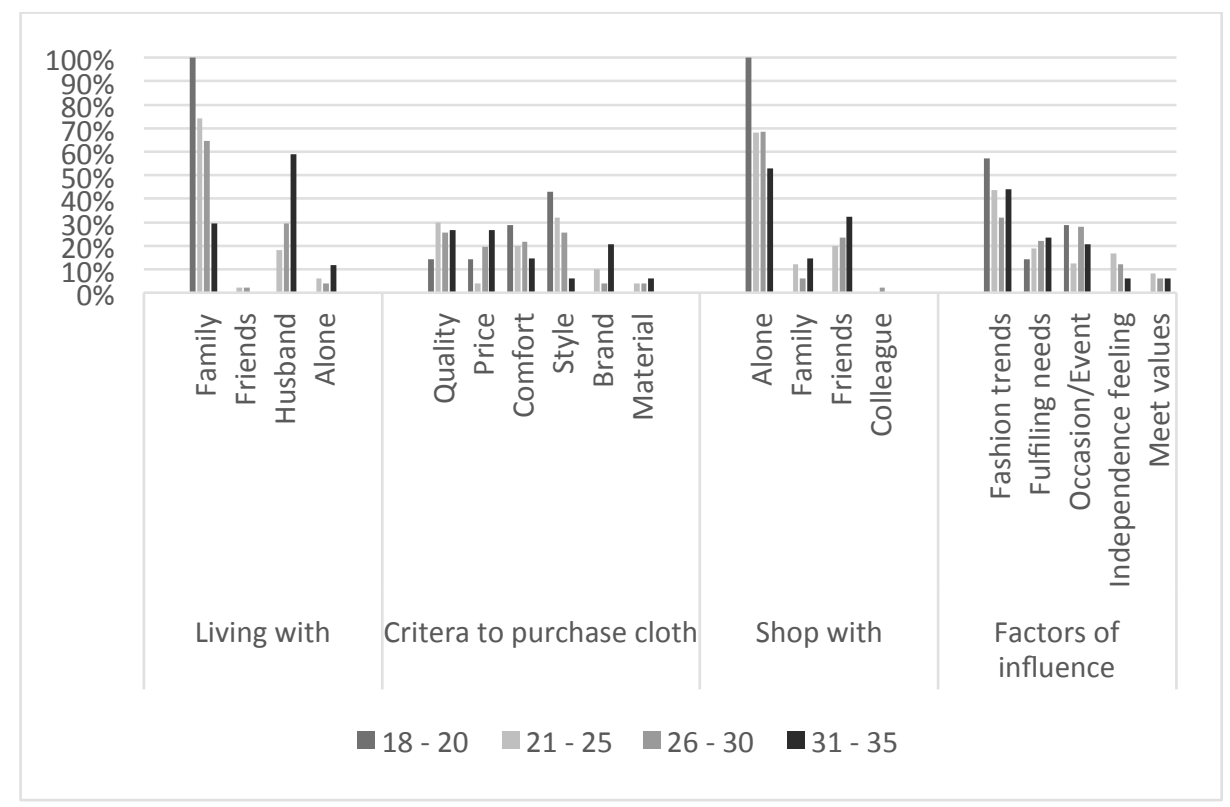

Fig. 4. Decision Making Factors against Age group

Out of all respondents, 54 (which is the largest group) agree that females who are financially dependent on males, significantly consider males views at the final stage of deciding to purchase. Only 26 respondents disagree to this statement, which suggests that a large number of young Pakistani women believe that females financially dependent on males are more likely to consider their views. This belief can be due to either personal experience or observation, as a large number or respondents live with their family, and are either students or married; i.e. financially dependent on males.

\subsection{Decision Making Influencing Factors according to Marital Status}

A large proportion of the sample (41 respondents) claimed that family suggestions were the most influential to making new purchases (29.1\%). 28 respondents $(19.9 \%)$ claimed that were influenced by friends, 27 respondents $(19.8 \%)$ were influenced by celebrity styles and 26 respondents $(18.4 \%)$ were influenced by spouses. However, $12.8 \%$ declared other factors.

Fig. 5. shows that 41 respondents $(29.5 \%)$ agreed that males from an extended family have an influential role towards the purchase clothing of young women. Whereas 40 respondents disagreed to the above given statement. Furthermore, 11 respondents strongly disagreed, hence if calculated larger number of respondents disagree that males from extended family play an influential role towards the purchase of fashion clothing. 


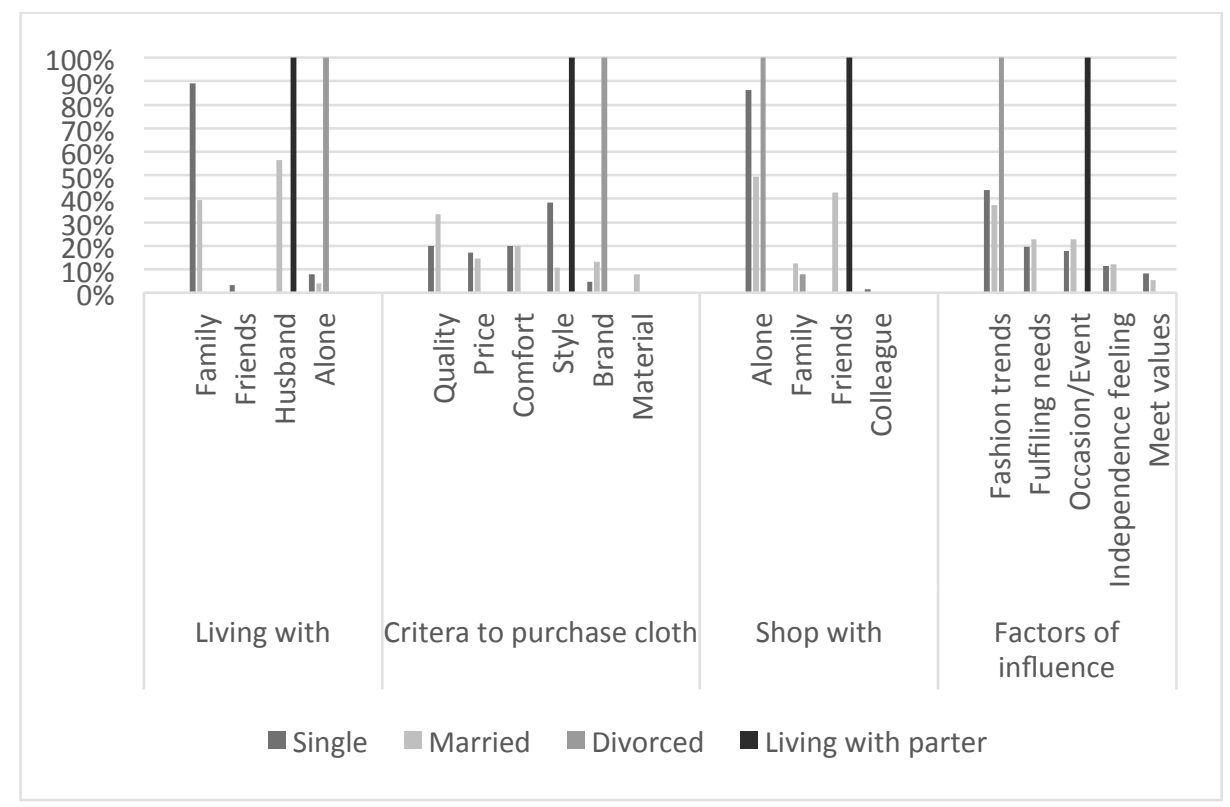

Fig. 5. Decision Making Factors against Marital Status

The second most important factor for deciding to purchase is 'a husband's suggestion', as given by 40 respondents $(28.8 \%)$. 'A friend's suggestion' was the next most important factor given by 32 (25.80) respondents; a 'Celebrities style' was chosen by $27(21.77 \%)$ respondents and 'a family suggestion' by $25(20.16 \%)$ respondents. This suggests that 'family, friend or husband suggestion', are the main factors that encourage young Pakistani women to purchase something new. This study proposes that male dominance plays the most critical part and role in influencing the decision process and purchases of young Pakistani women. Although, it is important to understand and distinguish between the influence of closely related males and males from the extended family. Results suggest that young Pakistani women are not influenced by male extended family members including uncles, cousins etc. However, when young Pakistani women (single or married) that are influenced by males were asked whether they are influenced by extended family males, they refused to answer. This may be associated with a growing desire to have a more individualistic lifestyle. Males who are directly related to these young women (their fathers, brothers and husbands) who they have regular contact with, have the greatest influence on purchasing decisions. Males from the extended family do not have an influence on purchasing, as it is very unlikely that these men would be aware of the woman's clothing consumption.

\subsection{Education and Buying Behavior}

It is believed that women's rational decision making is also influenced by emotion. Women think more contextually and holistically. To observe this and as well to relate 
that either women only take opinions of others whilst they are living with influential people or they undergo this process at all times, despite whomever they live with the following cross tabulation is shown in Fig. 6.

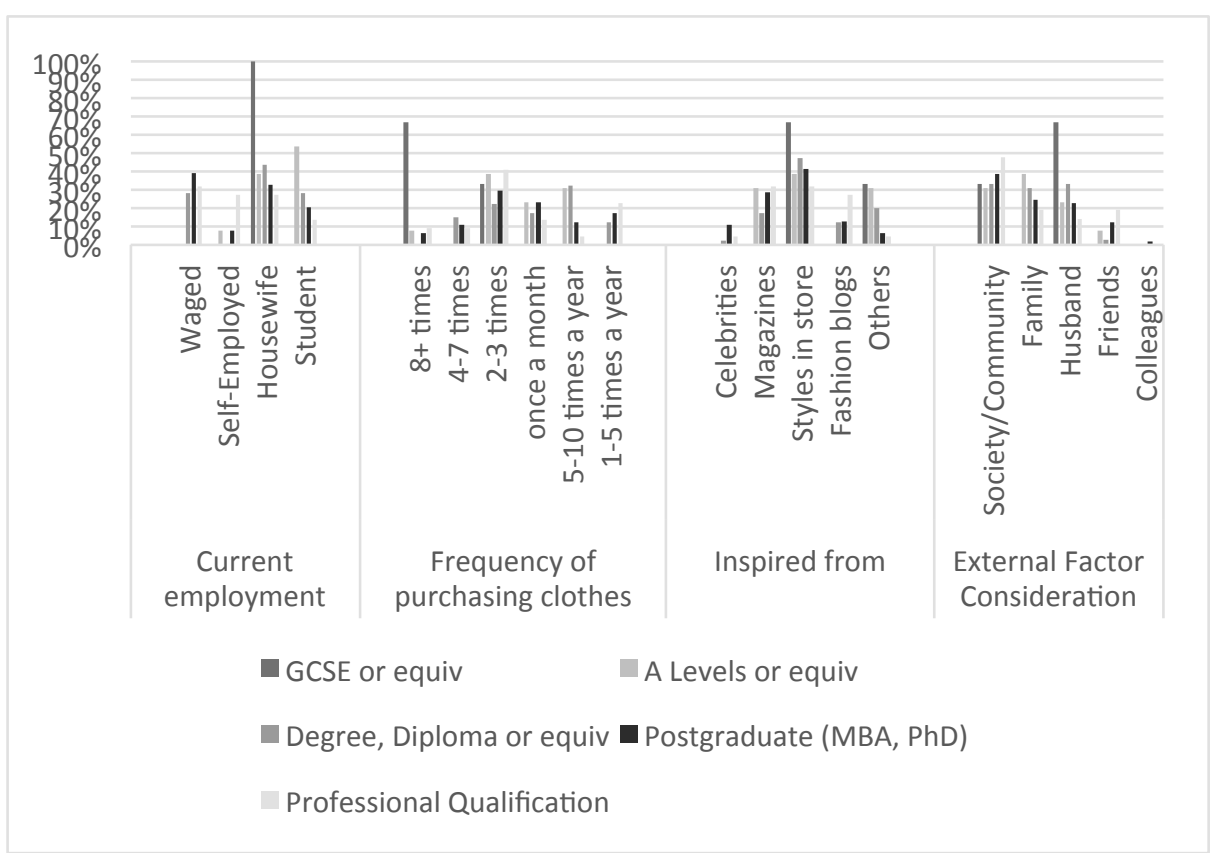

Fig. 6. Highest Level of Education and Buying Behavior

These results suggest that despite living circumstances (e.g. financial independence), Pakistani female consumers are influenced by their family, society, and colleagues; particularly males. They undergo an extensive thinking process, where they place their beliefs first, and these beliefs are the perceptions of the expected reaction from the society of males of undergoing a certain action. In fact, $47.2 \%$ of the total respondents did not purchase the clothes they preferred, suggesting that influencers (as mentioned above) enforce restrictions and set criteria, thereby limiting Pakistani females ability of carrying out independent purchase decisions.

\section{Conclusion}

Pakistani females (of any marital status) are influenced by males in their e-retailing decisions. They not only change their e-retailing decision at the last stage of the decision-making process but, also, in many cases, they allow males to make their fashion clothing purchase decision. The data suggests that when it comes to on-line shopping and e-commerce, young educated adult Pakistani females make on-line purchase decisions under a significant influence of a highly collective and masculine 
environment. The case study and results also demonstrate this to be true for the Pakistani society when shopping in-stores as well, but by extrapolating these findings, this is very likely to be true in several similar emerging markets in the same geographic region. Although, the empirical data gathering was in relation to fashion clothing, it is believed that the same results will also apply to other e-retailing areas.

The external influencing factors were society, family, spouse and colleagues for on-line decision-making in e-commerce platforms. The 'traditional family structures' and 'collective society' may change the final purchase decision of young adult women in emerging markets. Furthermore, from the perspective of decision-making process model [16], theory of reasoned action $[17,18]$ and attitude model, they appear to adopt a thinking process under which their purchasing choices are shaped by the reaction of their male counterparts when purchasing a product on-line. It has been observed as a whole, that the majority of the females, either single or married, are influenced by males to such an extent that not only can they change their decision at the last stage due to their influence, but also allow them to make their decisions.

For the development of e-commerce interfaces, this data suggests that the interaction and marketing presentation must be suitable and appeal not only to the purchaser (i.e. adult female) but also to the males in their immediate environment. Given the strong influence of males, the associated reviews of a product must also depict the gender of the reviewer given that a review from a male even for a female product is expected to have stronger influence than the same review originated by a female. This emerging paradigm of e-commerce transaction in developing markets is somewhat different to the traditional e-commerce interface approach that is traditionally used in developed markets.

\section{$5 \quad$ References}

1. Bearden, William O., Richard Netemeyer, \& Jeese Teel (1989), "Measurement of Consumer Susceptibility to Interpersonal Influence," Journal of Consumer Research 15 473481

2. Pakistan Infrastructure Report - 2014 2014, Business Monitor International, London.

3. Eric J. Arnould and Craig J. Thompson, (2005), Consumer Culture Theory (CCT): Twenty Years of Research, The Journal of Consumer Research, Vol. 31, No. 4 (March 2005), pp. 868-882

4. Brey, P. (2006). 'Evaluating the Social and Cultural Implications of the Internet,' Computers and Society 36(3), 41-48.

5. Saqib Ilyas, 2011, An Integrative Framework for Consumer Behavior: Evidence from Pakistan, International Journal of Business and Management, Vol. 6, No. 4; April 2011

6. Luna, D., \& Gupta, F.S. (2001). An integrative framework for cross-cultural consumer behavior. International

7. Traindis, H.C., Chan, D.K-S, Bhawuk, D.P.S, Iwao, S. and Sinha, J.B.P (1995) Multimethod Probes of allocentrism and idiocentrism, International Journal of Psychology, 54, 323-338

8. Triandis, H. C. (1994). Culture and social behavior. New York: McGraw-Hill 
9. Bagozzi, R., et al., 2002. The Social Psychology of Consumer Behaviour. Buckingham: Open University Press.

10. McCrae, R. R., \& Costa, P. T. (1994). The stability of personality: observation and evaluations. Current Directions in Psychological Science, 3, 173-175.

11. Żelazna K., Kowalczuk I., Mikuta B., (2002), Ekonomika konsumpcji, elementy teorii, Szkoła Główna Gospodarstwa Wiejskiego, Warszawa.

12. Keegan, W.J. \& Green, M.C. 2015, Global marketing, Pearson, Boston, Mass.

13. Streeter, L.G. 2007, Brush up on ABCs of model behaviour: Final Edition, Infomart, a division of Postmedia Network Inc, Edmonton, Alta.

14. Mooij, Marieke de. Hofstede, Geert. (2011) Cross-Cultural Consumer Behavior: A Review of Research Findings, Journal of International Consumer Marketing, 23:181-192, 2011

15. Chang, P., \& Chieng, M. (2006). Building consumer-brand relationship: A cross-cultural experience view. Psychology \& Marketing, 23(11), 927-959.

16. Engel, J.F., Kollat, D.T. \& Blackwell, R.D. Consumer behavior. New York: Holt, Rinehart \& Winston, 1968

17. Fishbein M and Ajzen I (1975) Belief, Attitude, Intention and Behaviour: An Introduction to Theory and Research, Addison -Wesley, Reading, MA

18. Fishbein, M. and Stasson, M. (1990) The role of desires, self-predictions, and perceived control in the prediction of training session attendance, Journal of Applied Social Psychology, 20:173-98

19. Rigas, D.I. and J.L. Alty, Using sound to communicate program execution. Proceedings of the 24th EUROMICRO Conference, 1998. 2: p. 625-632.

20. Rigas, D.I., Guidelines for Auditory Interface Design: An Empirical Investigation. 1996: $\mathrm{PhD}$ thesis, Loughborough University of Technology.

21. Hofstede, G. (1997) Cultures and Organizations: Software of the Mind, London: McGrawHill.

22. Yan Luo (2009).Analysis of Culture and Buyer Behavior in Chinese Market. Journal of Asian Culture and History, 1(1). 